\title{
Thrombocytopenia in neonates and the risk of intraventricular hemorrhage: a retrospective cohort study
}

\author{
Jeannette $S$ von Lindern ${ }^{1,2^{*}+}$, Tjitske van den Bruele ${ }^{1,2+}$, Enrico Lopriore ${ }^{1}$, Frans J Walther ${ }^{1}$
}

\begin{abstract}
Background: The overall prevalence of thrombocytopenia in neonates admitted to neonatal intensive care units ranges from 22 to $35 \%$. There are only a few small studies that outline the relationship between the severity of thrombocytopenia and the risk of bleeding. This makes it difficult to form an evidence-based threshold for platelet transfusions in neonatal patients. The aim of this study was to determine the prevalence of thrombocytopenia in a tertiary neonatal intensive care unit and to study the relation between thrombocytopenia and the risk of intraventricular hemorrhage (IVH).

Methods: We performed a retrospective cohort study of all patients with thrombocytopenia admitted to our neonatal tertiary care nursery between January 2006 and December 2008. Patients were divided into 4 groups according to the severity of thrombocytopenia: mild (100-149 $\left.\times 10^{9} / \mathrm{L}\right)$, moderate $\left(50-99 \times 10^{9} / \mathrm{L}\right)$, severe $(30-49 \times$ $\left.10^{9} / \mathrm{L}\right)$ or very severe $\left(<30 \times 10^{9} / \mathrm{L}\right)$. The primary outcome was $\mathrm{IVH} \geq$ grade 2 . Pearson's chi-squared and Fischer's exact tests were used for categorical data. ANOVA, logistic regression analysis and multivariate linear regression were used for comparisons between groups and for confounding factors.

Results: The prevalence of thrombocytopenia was 27\% (422/1569). Risk of IVH $\geq$ grade 2 was 12\% (48/411) in neonates with versus $5 \%(40 / 844)$ in neonates without thrombocytopenia $(p<0.01)$. After multivariate linear regression analysis, risk of $\mathrm{IVH} \geq$ grade 2 in the subgroups of thrombocytopenic infants was not significantly different $(p=0.3)$.

After logistic regression analysis the difference in mortality rate in neonates with and without thrombocytopenia was not significant $(p=0.4)$. Similarly, we found no difference in mortality rate in the subgroups of neonates with thrombocytopenia $(p=0.7)$.

Conclusion: Although $\mathrm{IVH} \geq$ grade 2 occurs more often in neonates with thrombocytopenia, this relation is independent of the severity of thrombocytopenia. Prospective studies should be conducted to assess the true risk of hemorrhage depending on underlying conditions. Randomized controlled trials are urgently needed to determine a safe lower threshold for platelet transfusions.
\end{abstract}

\section{Background}

The overall prevalence of thrombocytopenia in neonates ranges from 1 to $5 \%$ [1-3] and is reported to be much higher in neonates admitted to neonatal intensive care units, ranging from 22 to $35 \%$ [1-6]. From 22 weeks' gestation onwards, the platelet count reaches and

\footnotetext{
* Correspondence: J.S.von_lindern@lumc.nl

† Contributed equally

'Division of Neonatology J6-S, Department of Pediatrics, Leiden University

Medical Center, PO Box 9600, 2300 RC Leiden, The Netherlands

Full list of author information is available at the end of the article
}

maintains a level above $150 \times 10^{9} / \mathrm{L}$, thereby defining thrombocytopenia in the newborn as a platelet count below $150 \times 10^{9} / \mathrm{L}[1,2]$. Many neonatal and maternal conditions are associated with thrombocytopenia, of which septicemia and prematurity are the most common $[2,6]$. In thrombocytopenia the major concern is an increased risk of bleeding.

In 1882 Bizzozzero was the first to describe the role of platelets in coagulation and thrombosis [7]. Since then, only a few small studies investigating the relationship between the severity of thrombocytopenia and the risk

\section{Biomed Central}


of bleeding in newborns have been reported $[4,8,9]$. Likewise, the number of clinical trials examining thrombocytopenia and the effects on bleeding in adults is limited [10-13]. The lack of studies makes it difficult to form an evidence-based threshold for platelet transfusions in neonatal patients.

The aim of this study was to analyze and describe all cases with thrombocytopenia admitted to our neonatal nursery during a 3-year period and study a possible relationship between the risk of intraventricular hemorrhage (IVH) and the severity of thrombocytopenia. We studied the prevalence and risk factors of thrombocytopenia in relation to the risk of IVH and mortality.

\section{Methods}

\section{Patients}

We retrospectively collected data from all neonates admitted between January 2006 and December 2008 to the neonatal department of the Leiden University Medical Center, a tertiary neonatal care center in The Netherlands. In the Netherlands no ethical approval is required for this type of research as no new intervention or treatment is studied. Nor is any randomization needed. All collected data was anonymized. We identified all thrombocytopenic newborns by extracting data from our dedicated patient-database, medical files, laboratory system and electronic blood banking records. We excluded neonates with only one platelet count measurement below $150 \times 10^{9} / \mathrm{l}$. We considered these isolated counts as clotted samples, platelet clumping, laboratory error or one-time only measurements with immediate normalization. Thrombocytopenia was defined as a platelet count below $150 \times 10^{9} / \mathrm{L}$. The included neonates with thrombocytopenia were divided into 4 groups, based on their lowest platelet count during their stay in our unit, and classified as mild (platelet count $100-149 \times 10^{9} / \mathrm{L}$ ), moderate (platelet count 50-99 $\times 10^{9} / \mathrm{L}$ ), severe (platelet count $30-49 \times 10^{9} / \mathrm{L}$ ) or very severe (platelet count $<30 \times 10^{9} / \mathrm{L}$ ), according to standard classification [1,2,6,14-17].

We recorded the presence of IVH detected by cranial ultrasound and classified according to Volpe [18]. IVH grade 2, grade 3 or grade 4 (i.e. periventricular hemorrhagic infarction (PVHI)) were recorded.

Cranial ultrasounds were performed according to local protocol depending on gestational age and degree of illness.

Data for demographic as well as clinical conditions of all infants were collected, including gender, gestational age at birth, birth weight, small for gestational age, chromosomal disorders, perinatal asphyxia, necrotizing enterocolitis, sepsis/meningitis, hemorrhage, thrombosis, central catheters, polycythemia, rhesus hemolytic disease, exchange transfusion, neonatal allo-immune thrombocytopenia and the number of blood product transfusions (platelets, erythrocytes, fresh frozen plasma). Small for gestational age was defined as a birth weight $<3^{\text {rd }}$ percentile for the corresponding gestational age [19]. Chromosomal disorders were defined as congenital anomalies related to thrombocytopenia, such as trisomy 18 and 21. Perinatal asphyxia was defined as a five minute Apgar score $<5$, a decelerative heart rate on a cardiotocogram and/or an arterial umbilical cord $\mathrm{pH}$ below 7.0. Hypotension was defined as a mean blood pressure below the $3^{\text {rd }}$ percentile for gestational age and requiring inotropic support. Sepsis was defined as a positive blood culture in a neonate with clinical signs of infection. Necrotizing enterocolitis was scored based on Bell staging criteria [20]. Polycythemia was defined as a venous hematocrit $\geq 65 \%$ in symptomatic infants or $\geq$ $70 \%$ with or without symptoms. A thrombus could be catheter related, in a major blood vessel or intracardial, detected with ultrasound.

The primary outcome measure was IVH $\geq$ grade 2 . The secondary outcomes were total number of platelet transfusions and mortality.

In our hospital a platelet transfusion for neonates is a concentrated single donor product in plasma and is leukocyte depleted. The dose is a median of $20 \times 10^{9}$ platelets per $\mathrm{kg}$. The product is irradiated with $25 \mathrm{~Gy}$ for all infants with a gestational age below 32 weeks and/or a birth weight below 1500 grams and/or for neonates that previously underwent an intra-uterine transfusion. Guidelines for platelet transfusions in our department were as follows: 1) platelet count $<30 \times 10^{9} / \mathrm{L}$ and stable, 2) platelet count $<50 \times 10^{9} / \mathrm{L}$ and unstable, and/ or birth weight $<1000 \mathrm{~g}$, and/or previous major bleeding, and/or after exchange transfusion, and/or before planned surgery and/or rapid decrease of platelets, or 3) platelet count $<100 \times 10^{9} / \mathrm{L}$ in neonates with active bleeding and/or at start of exchange transfusion [17].

\section{Statistics}

Data analyses were performed using Statistical Package for Social Sciences (SPSS), version 16.0 (SPSS, Inc., Chicago, Illinois, USA). For every separate variable the Pearson's chi-squared test was used. If the chi-squaredtest could not be used (frequency of an event was $<5)$ the Fisher's exact test was used. Comparisons between group means were analyzed using the one way ANOVA test (with a 95\% confidence-interval). Logistic regression was performed to evaluate the confounders between the infants with and without thrombocytopenia. Factors considered potential confounders were variables with a significant difference in thrombocytopenia. Multivariate linear regression was used to compare for confounders in the subgroups of thrombocytopenic neonates, because of the small number in some of the 
subgroups of thrombocytopenic neonates. A p-value smaller than 0.05 was considered to be significant.

\section{Results}

Total patient population

A total of 1727 neonates were admitted to our neonatal nursery during the 3-year study period. Thrombocytopenia was detected in 580 neonates, of which 158 were excluded because of only one platelet count below $150 \times$ $10^{9} / \mathrm{L}$. The prevalence of thrombocytopenia was $27 \%$ $(422 / 1569)$. Neonates with thrombocytopenia were divided into four groups according to their lowest platelet count; 122 (29\%) mild, 164 (39\%) moderate, 67 (16\%) severe and $69(16 \%)$ with very severe thrombocytopenia. The distribution of included and excluded neonates is shown in Figure 1.

An overview of the baseline characteristics of all included neonates with $(\mathrm{n}=422)$ and without $(\mathrm{n}=$ 1147) thrombocytopenia is presented in Table 1. Except for gender, single or multiple births and chromosomal disorders, every characteristic was significantly different.

\section{Primary and secondary outcome in total patient population}

Cranial ultrasound was performed in 97\% (411/422) of neonates with thrombocytopenia and in 74\% (844/1147) of infants without thrombocytopenia. The rate of IVH $\geq$ grade 2 in neonates with and without thrombocytopenia was $12 \%(48 / 411)$ and $5 \%(40 / 844)$, respectively ( $\mathrm{p}<$ $0.01)$. After multiple regression analysis, with all significantly different variables, the correlation between IVH and thrombocytopenia was still statistically significant $(\mathrm{p}=0.045)$; gestational age remained an independent significant risk factor for IVH $(\mathrm{p}<0.01)$.

Mortality rate in neonates with and without thrombocytopenia, respectively 9\% (39/422) vs. 3\% (32/1147), was not significantly different after multiple regression analysis $(\mathrm{p}=0.4)$.

\section{Thrombocytopenic patient population}

Thrombocytopenia was detected at a mean of 2 days after birth (range 0-56 days). In the group of thrombocytopenic neonates $(n=422), 27$ died before thrombocytopenia had resolved and in 32 neonates laboratory testing was discontinued before a platelet count above $150 \times 10^{9} / \mathrm{L}$ was recorded during follow-up. In these 32 infants platelet counts were not measured because of already increasing platelet counts with a value above $120 \times 10^{9} / \mathrm{L}$. In the remaining 363 neonates, the mean duration of thrombocytopenia was 9 days (range 0-112 days). We found a significant positive correlation between severity of thrombocytopenia and the time to recovery. Duration of thrombocytopenia in the mild, moderate, severe and very severe group was 5, 8, 10 and 16 days, respectively ( $\mathrm{p}<0.01)$.

Mean gestational age at birth was 32.5 (range 24 to 42 ) weeks. Of all thrombocytopenic neonates, 75\% (316/422) were preterm ( $<37$ weeks). Patient characteristics divided into subgroups according to severity of thrombocytopenia are shown in Table 2. After linear regression analysis,

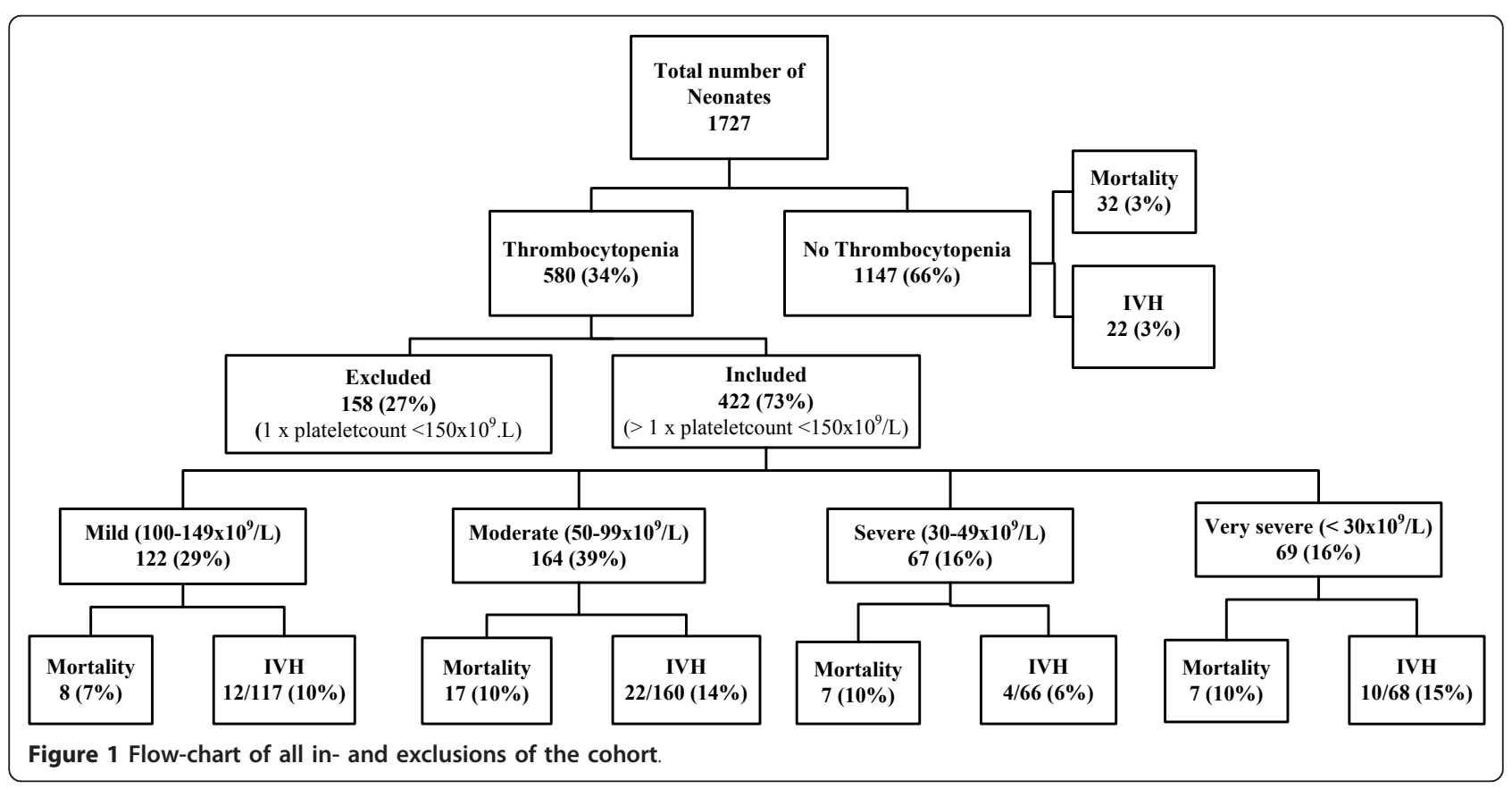


Table 1 Patient characteristics of neonates with and without thrombocytopenia

\begin{tabular}{|c|c|c|c|}
\hline & $\begin{array}{l}\text { Neonates without thrombocytopenia } \\
\qquad(\mathrm{N}=1147)\end{array}$ & $\begin{array}{l}\text { Neonates with thrombocytopenia } \\
\qquad(\mathrm{N}=422)\end{array}$ & P-value \\
\hline Female gender, n (\%) & $513(45)$ & $179(42)$ & 0.41 \\
\hline GA at birth (weeks), mean \pm SD & $35 \pm 4.2$ & $32.5 \pm 4.8$ & $<0.01$ \\
\hline Birth weight (gram), mean \pm SD & $2537 \pm 968$ & $1864 \pm 1067$ & $<0.01$ \\
\hline SGA, n (\%) & $44(4)$ & $62(15)$ & $<0.01$ \\
\hline Multiple births (single), n (\%) & $270(24)$ & $100(24)$ & 0.96 \\
\hline \multicolumn{4}{|l|}{ Postnatal condition } \\
\hline Asphyxia, n (\%) & $42(4)$ & $46(11)$ & $<0.01$ \\
\hline Hypotension, n (\%) & $68(6)$ & $123(29)$ & $<0.01$ \\
\hline Sepsis, n (\%) & $77(7)$ & $129(30)$ & $<0.01$ \\
\hline NEC, n (\%) & $9(1)$ & $10(2)$ & 0.01 \\
\hline Central catheter, n (\%) & $403(35)$ & $346(82)$ & $<0.01$ \\
\hline Thrombus, n (\%) & $6(1)$ & $14(3)$ & $<0.01$ \\
\hline NAITP, n (\%) & $1(0)$ & $14(3)$ & $<0.01$ \\
\hline Polycythemia, n (\%) & $32(3)$ & $26(6)$ & $<0.01$ \\
\hline $\mathrm{RHD}, \mathrm{n}(\%)$ & $61(5)$ & $40(10)$ & $<0.01$ \\
\hline Exchange transfusion, n (\%) & $1(0)$ & $14(3)$ & $<0.01$ \\
\hline Chromosomal disorders, n (\%) & $9(1)$ & $7(2)$ & 0.15 \\
\hline
\end{tabular}

GA = gestational age, SGA = small for gestational age, NEC $=$ necrotizing enterocolitis, NAITP $=$ Neonatal alloimmune thrombocytopenia, RHD $=$ Rhesus Hemolytic Disease.

severity of thrombocytopenia remained associated with sepsis $(\mathrm{p}<0.01)$ and thrombi $(\mathrm{p}<0.01)$.

In $66 \%$ of the 105 thrombocytopenic neonates with sepsis, the low platelet count was already present before the child became ill, whereas in 15\% thrombocytopenia developed after the onset of sepsis.
Primary and secondary outcome in thrombocytopenic patient population

In the majority (87\%) of neonates with an IVH $\geq$ grade 2 the hemorrhage occurred within the first 3 days of life. In $23 \%$ of the 48 neonates $(11 / 48)$ with an IVH, the hemorrhage was discovered on the same day as the

Table 2 Patient characteristics of thrombocytopenic neonates, divided into subgroups by severity

\begin{tabular}{|c|c|c|c|c|c|}
\hline & $\begin{array}{c}\text { Mild } \\
\left(100-149 \times 10^{9} / \mathrm{L}\right) \\
(\mathrm{N}=122)\end{array}$ & $\begin{array}{c}\text { Moderate } \\
\left(50-99 \times 10^{9} / \mathrm{L}\right) \\
(\mathrm{N}=164)\end{array}$ & $\begin{array}{c}\text { Severe } \\
\left(30-49 \times 10^{9} / \mathrm{L}\right) \\
(\mathrm{N}=67)\end{array}$ & $\begin{array}{c}\text { Very severe } \\
\left(<30 \times 10^{9} / \mathrm{L}\right) \\
(\mathrm{N}=69)\end{array}$ & P-value \\
\hline Gender (female), n (\%) & $51(42)$ & $66(40)$ & $32(48)$ & $30(43)$ & 0.77 \\
\hline GA (weeks), mean \pm SD & $32.8 \pm 4.7$ & $32.1 \pm 4.7$ & $32.5 \pm 4.7$ & $32.9 \pm 5.0$ & 0.56 \\
\hline Weight (gram), mean \pm SD & $2004 \pm 1172$ & $1715 \pm 984$ & $1854 \pm 1058$ & $1979 \pm 1046$ & 0.11 \\
\hline$\overline{S G A, n(\%)}$ & $13(11)$ & $29(18)$ & $12(18)$ & $8(12)$ & 0.28 \\
\hline \multicolumn{6}{|l|}{ Postnatal condition } \\
\hline Asphyxia, n (\%) & $11(9)$ & $14(9)$ & $9(13)$ & $12(17)$ & 0.19 \\
\hline Hypotension, n (\%) & $27(22)$ & $46(28)$ & $28(42)$ & $22(32)$ & 0.04 \\
\hline Sepsis, n (\%) & $26(21)$ & $43(26)$ & $25(37)$ & $35(51)$ & $<0.01$ \\
\hline $\mathrm{NEC}, \mathrm{n}(\%)$ & $1(1)$ & $4(2)$ & $3(4)$ & $2(3)$ & * \\
\hline Central catheter, n (\%) & $90(74)$ & $138(84)$ & $56(84)$ & $62(90)$ & 0.03 \\
\hline Thrombus, n (\%) & $2(2)$ & $3(2)$ & $3(4)$ & $6(9)$ & * \\
\hline NAITP, n (\%) & $1(1)$ & $5(3)$ & $5(8)$ & $3(4)$ & * \\
\hline Polycythemia, n (\%) & $6(5)$ & $12(7)$ & $3(5)$ & $5(7)$ & $*$ \\
\hline RHD, n (\%) & $7(6)$ & $13(8)$ & $8(12)$ & $12(17)$ & 0.05 \\
\hline Exchange transfusion, n (\%) & $1(1)$ & $4(2)$ & $2(3)$ & $7(10)$ & * \\
\hline Chromosomal disorders, n (\%) & $0(0)$ & $2(1)$ & $1(1)$ & $4(6)$ & * \\
\hline
\end{tabular}

* = No analysis possible, because some of the subgroups were too small.

$\mathrm{GA}=$ gestational age, $\mathrm{SGA}=$ small for gestational age, NEC = necrotizing enterocolitis, FFP = fresh frozen plasma, NAITP $=$ Neonatal alloimmune thrombocytopenia, RHD = Rhesus Hemolytic Disease. 
thrombocytopenia. In 20 (42\%) neonates the hemorrhage was discovered after and in 16 (33\%) before the thrombocytopenia even existed. In 1 neonate we could not trace the timing of the hemorrhage.

Among the 122 neonates who received a platelet transfusion 17 had an IVH $\geq$ grade 2 . Two (13\%) of these infants developed an IVH during thrombocytopenia despite platelet transfusions (one IVH grade 2, one IVH grade 3 ).

The primary and secondary outcome in the 4 subgroups of neonates with thrombocytopenia is presented in Table 3. Risk of hemorrhage was 10\% (12/117), 14\% $(22 / 160), 6 \%(4 / 66)$ and $15 \%(10 / 68)$. We found no significant association between bleeding and severity of thrombocytopenia $(\mathrm{p}=0.3)$. After logistic regression analysis, the severity of thrombocytopenia was not a significant risk factor for IVH.

Logistic regression analysis showed no significant relation between mortality and the severity of thrombocytopenia $(\mathrm{p}=0.7)$. In 5 patients treatment was withdrawn because of poor neurological prognosis due to major hemorrhage (IVH grade 3 or PVHI) in combination with respiratory and/or cardiac insufficiency.

Of all included neonates with thrombocytopenia 29\% $(122 / 422)$ received a platelet transfusion (Table 3$)$. The median number of platelet transfusions in the mild, moderate, severe and very severe groups was $0,1,1$ and 3 , respectively. The 9 neonates in the moderate thrombocytopenia group $\left(50-99 \times 10^{9} / \mathrm{L}\right)$ were transfused because of a rapid drop in platelet count in combination with sepsis $(n=4)$, IVH $\geq$ grade $2(n=3)$ or adrenal hemorrhage $(n=1)$. In most cases the infants with severe thrombocytopenia $\left(30-49 \times 10^{9} / \mathrm{L}\right)$ received a platelet transfusion before or during an intervention (such as a lumbar puncture or exchange transfusion), because of active bleeding or if they were clinically unstable. The rest of the newborns were transfused when the platelet count was below $30 \times 10^{9} / \mathrm{L}$. Only 4 neonates with very severe thrombocytopenia did not receive a platelet transfusion. Three of them had a gestational age of 37 and the fourth one of 31 weeks. All four were clinically stable, 2 had polycythemia and 2 had Rhesus hemolytic disease. None of them had IVH.

\section{Discussion}

This study shows that although thrombocytopenic neonates are a high risk group (more unstable, and sicker than non-thrombocytopenic neonates), the severity of thrombocytopenia is not related to IVH or mortality. In $33 \%$ of the thrombocytopenic neonates with IVH grade 2 or more, IVH occurred before the thrombocytopenia even existed. Our data confirm that risk of IVH in neonates is a complex mechanism related to a wide variety of factors, of which low platelet counts is only one.

\section{Prevalence of thrombocytopenia}

The overall prevalence of thrombocytopenia found in this study $(27 \%)$ is in accordance with the rates reported in the literature for tertiary care centers (22-35\%) [1-6]. The prevalence of severe $\left(<50 \times 10^{9} / \mathrm{L}\right)$ thrombocytopenia $(8 \%)$ was also similar to other studies (2-25\%) [1,3].

Our findings confirm that thrombocytopenia in neonates is associated with a wide variety of factors, including prematurity and low birth weight, small for gestational age, sepsis, hypotension, necrotizing enterocolitis, asphyxia, thrombi and exchange transfusions $[1,4,14,21]$.

\section{Platelet transfusion}

We found a positive correlation between the severity of thrombocytopenia, the duration of thrombocytopenia and with the total number of platelet transfusions. In the subgroup of infants with severe thrombocytopenia, platelet transfusion resulted in a good, but less sustained rise in platelet count (data not shown). A few studies have suggested that a fast drop in platelet count after

Table 3 Primary and secondary outcome in the 4 subgroups of thrombocytopenic neonates

\begin{tabular}{|c|c|c|c|c|c|}
\hline & $\begin{array}{c}\text { Mild } \\
\left(100-149 \times 10^{9} / \mathrm{L}\right) \\
\end{array}$ & $\begin{array}{c}\text { Moderate } \\
\left(50-99 \times 10^{9} / \mathrm{L}\right) \\
\end{array}$ & $\begin{array}{c}\text { Severe } \\
\left(30-49 \times 10^{9} / L\right)\end{array}$ & $\begin{array}{c}\text { Very severe } \\
\left(<30 \times 10^{9} /\right)\end{array}$ & P-value \\
\hline & $(N=122)$ & $(N=164)$ & $(N=67)$ & $(\mathrm{N}=69)$ & \\
\hline Primary Outcome & $(N=117)$ & $(\mathrm{N}=160)$ & $(\mathrm{N}=66)$ & $(\mathrm{N}=68)$ & \\
\hline Number of neonates with $\mathrm{IVH} \geq$ grade $2, \mathrm{n}(\%)$ & $12(10)$ & $22(14)$ & $4(6)$ & $10(15)$ & 0.32 \\
\hline $\mathrm{IVH}$, grade 2 & $3(3)$ & $7(4)$ & $3(5)$ & $6(9)$ & 0.26 \\
\hline $\mathrm{IVH}$, grade 3 & $4(3)$ & $6(4)$ & $1(2)$ & $2(3)$ & 0.86 \\
\hline PVHI (i.e., IVH grade 4) & $5(4)$ & $9(6)$ & $0(0)$ & $2(3)$ & 0.25 \\
\hline Secondary Outcome & $(N=122)$ & $(\mathrm{N}=164)$ & $(\mathrm{N}=67)$ & $(\mathrm{N}=69)$ & \\
\hline Number of platelet Txs per transfused patient, median (range), N & $\begin{array}{c}0 \\
(N=0)\end{array}$ & $\begin{array}{l}1(1-1) \\
(\mathrm{N}=9)\end{array}$ & $\begin{array}{c}1(1-5) \\
(N=48)\end{array}$ & $\begin{array}{l}3(1-28) \\
(N=65)\end{array}$ & $<0.01$ \\
\hline Mortality, n (\%) & $8(7)$ & $17(10)$ & $7(10)$ & $7(10)$ & 0.69 \\
\hline
\end{tabular}

$\mathrm{IVH}=$ intraventricular hemorrhage, $\mathrm{PVHI}=$ periventricular hemorrhagic infarction, $\mathrm{Txs}=$ transfusions. 
transfusion is caused by ongoing platelet consumption instead of platelet underproduction [21].

The reason for platelet transfusions in more than half of the cases was an existing thrombocytopenia. Despite the platelet transfusions, $13 \%(2 / 17)$ developed an IVH ( $\geq$ grade 2 ), independent of the severity of thrombocytopenia. In newborns that required more transfusions (data not shown) no increased risk for IVH was seen, comparable to other studies $[9,16,21]$. Therefore the jury is still out on the protective value of platelet transfusions $[1,4,6,9,22]$.

\section{Risk of hemorrhage}

We found no significant relationship between hemorrhage and severity of thrombocytopenia. This suggests that bleeding in neonates depends on more variables than a platelet count alone. In approximately one-third of the thrombocytopenic neonates the IVH was discovered before the thrombocytopenia existed and this raises the question whether IVH can be explained as a cause or an effect of thrombocytopenia [22-24]. Hemorrhage is probably due to pre-existing fragility in vessel wall structure (especially in premature neonates) and damaged blood vessels, amongst others by cytokines and/or a co-existing coagulopathy $[9,22]$.

Our results are important in the discussion whether thrombocytopenia is one of the major causes of IVH in neonates. Major IVH has a large impact on neurological development and mortality. However, the risk for an IVH cannot be predicted based on a platelet count alone. We also looked at other bleedings of importance in the thrombocytopenic neonates, such as pulmonaryor gastrointestinal bleedings, but the number of these hemorrhages was too small to analyze. Other variables such as gestational age, birth weight and underlying illness are of equal importance and should be taken into account. Several studies have searched for other factors that may influence the development of hemorrhage in thrombocytopenic neonates. Deficiencies, immaturity or increased consumption of other blood products, such as thrombopoietin, coagulation factors, megakaryocyte progenitor cells, cytokines and mean platelet volume, have been reported [3,25].

One of the current major issues in transfusion medicine is the appropriate trigger for platelet transfusion. Different triggers are being used for platelet transfusion. While some centers transfuse all neonates with platelet counts below $50 \times 10^{9} / \mathrm{L}$, other centers use lower thresholds such as $<30$ or $<20 \times 10^{9} / \mathrm{L}[1,2,14,17,26]$. There is an apparent evolvement amongst neonatologists towards more liberal platelet transfusion practices, even in the absence of evidence based data [27]. This study does not demonstrate a difference in IVH between neonates with a platelet count below $50 \times 10^{9} / \mathrm{L}$ or below $30 \times 10^{9} / \mathrm{L}$ (nor between $<150,<100$ or lower for that matter), questioning the different transfusion thresholds. Whether platelet transfusions have a protective value in neonates with a platelet count below $20 \times$ $10^{9} / \mathrm{L}$ is still not known.

\section{Conclusion}

In this study, we found no relationship between the severity of thrombocytopenia and IVH, suggesting that the etiology of IVH in neonates is a complex multifactorial process. However, our findings should be interpreted with care due to limitations associated with the retrospective nature of the study and the relatively small sample sizes of some variables in the subgroups.

Prospective studies should be conducted to assess the true risk of hemorrhage depending on underlying conditions. Randomized controlled trials are urgently needed to determine a safe lower threshold for platelet transfusions.

\section{Author details}

'Division of Neonatology J6-S, Department of Pediatrics, Leiden University Medical Center, PO Box 9600, 2300 RC Leiden, The Netherlands.

${ }^{2}$ Department of Pediatrics, Groene Hart Hospital, Gouda, The Netherlands.

\section{Authors' contributions}

JSVL and TrdB made substantial contributions to the study design, data retrieval and analysis and interpretation of the data. Both were involved in writing and revising the manuscript.

EL and FJW made substantial contributions to the acquisition of data,

interpretation of the data and critical revision of the manuscript. All authors have given approval of the final document.

\section{Competing interests}

The authors declare that they have no competing interests.

Received: 25 August 2010 Accepted: 11 February 2011

Published: 11 February 2011

\section{References}

1. Roberts I, Stanworth S, Murray NA: Thrombocytopenia in the neonate. Blood Rev 2008, 22:173-186.

2. Sola-Visner M, Saxonhouse MA, Brown RE: Neonatal thrombocytopenia: what we do and don't know. Early Hum Dev 2008, 84:499-506.

3. Sola MC, Rimsza LM: Mechanisms underlying thrombocytopenia in the neonatal intensive care unit. Acta Paediatr Suppl 2002, 91:66-73.

4. Christensen RD: Advances and controversies in neonatal ICU platelet transfusion practice. Adv Pediatr 2008, 55:255-269.

5. Del Vecchio A, Sola MC, Theriaque DW, Hutson AD, Kao KJ, Wright D, et al: Platelet transfusions in the neonatal intensive care unit:factors predicting which patients will require multiple transfusions. Transfusion 2001, 41:803-808.

6. Roberts I, Murray NA: Neonatal thrombocytopenia. Semin Fetal Neonatal Med 2008, 13:256-264.

7. Bizzozero J: Über einen neuen formbestandteil des blutes und dessen rolle bei der thrombose und blutgerinnung. Virchow's Arch Path Anat Physiol Klin Med 1882, 90:261-332.

8. Andrew M, Castle V, Saigal S, Carter C, Kelton JG: Clinical impact of neonatal thrombocytopenia. J Pediatr 1987, 110:457-464.

9. Andrew M, Vegh P, Caco C, Kirpalani H, Jefferies A, Ohlsson A, et al: A randomized, controlled trial of platelet transfusions in thrombocytopenic premature infants. J Pediatr 1993, 123:285-291.

10. Guidelines for the use of platelet transfusions. Br J Haematol 2003, 122:10-23. 
11. Delaney M, Meyer E, Cserti-Gazdewich C, Haspel RL, Lin Y, Morris A, et al: A systematic assessment of the quality of reporting for platelet transfusion studies. Transfusion 2010, 50:2135-2144.

12. Strauss $R$, Wehler M, Mehler K, Kreutzer D, Koebnick C, Hahn EG: Thrombocytopenia in patients in the medical intensive care unit: bleeding prevalence, transfusion requirements, and outcome. Crit Care Med 2002, 30:1765-1771.

13. Slichter SJ, Kaufman RM, Assmann SF, McCullough J, Triulzi DJ, Strauss RG, et al: Dose of prophylactic platelet transfusions and prevention of hemorrhage. N Engl J Med 2010, 362:600-613.

14. Het Kwaliteitsinstituut voor de Gezondheidszorg CBO: CBO-richtlijn bloedtransfusies. Alphen aan den Rijn, Van Zuiden Communications B.V 2004, 247-257.

15. Murray NA, Howarth LI, McCloy MP, Letsky EA, Roberts IA: Platelet transfusion in the management of severe thrombocytopenia in neonatal intensive care unit patients. Transfus Med 2002, 12:35-41.

16. Sola MC: Evaluation and treatment of severe and prolonged thrombocytopenia in neonates. Clin Perinatol 2004, 31:1-14.

17. von Lindern JS, Brand A: The use of blood products in perinatal medicine. Semin Fetal Neonatal Med 2008, 13:272-281.

18. Volpe JJ: Neurology of the newborn. 5 edition. Philadelphia: Saunders Elsevier; 2008.

19. Kloosterman GJ: [Intrauterine growth and intrauterine growth curves]. Ned Tijdschr Verloskd Gynaecol 1969, 69:349-365.

20. Neu J: Necrotizing enterocolitis: the search for a unifying pathogenic theory leading to prevention. Pediatr Clin North Am 1996, 43:409-432.

21. Bonifacio L, Petrova A, Nanjundaswamy S, Mehta R: Thrombocytopenia related neonatal outcome in preterms. Indian J Pediatr 2007, 74:269-274.

22. Stanworth SJ, Bennett C: How to tackle bleeding and thrombosis in the newborn. Early Hum Dev 2008, 84:507-513.

23. Baer VL, Lambert DK, Henry E, Christensen RD: Severe Thrombocytopenia in the NICU. Pediatrics 2009, 124:e1095-e1100.

24. Stanworth SJ, Clarke P, Watts T, Ballard S, Choo L, Morris T, et al: Prospective, Observational Study of Outcomes in Neonates With Severe Thrombocytopenia. Pediatrics 2009, 124(5):e826-34.

25. Sola-Visner M, Sallmon H, Brown R: New insights into the mechanisms of nonimmune thrombocytopenia in neonates. Semin Perinatol 2009, 33:43-51.

26. New HV, Stanworth SJ, Engelfriet CP, Reesink HW, McQuilten ZK, Savoia HF, et al: Neonatal transfusions. Vox Sang 2009, 96:62-85.

27. Josephson CD, Su LL, Christensen RD, Hillyer CD, Castillejo Ml, Emory MR, et al: Platelet transfusion practices among neonatologists in the United States and Canada: results of a survey. Pediatrics 2009, 123:278-285.

Pre-publication history

The pre-publication history for this paper can be accessed here: http://www.biomedcentral.com/1471-2431/11/16/prepub

doi:10.1186/1471-2431-11-16

Cite this article as: von Lindern et al: Thrombocytopenia in neonates and the risk of intraventricular hemorrhage: a retrospective cohort study. BMC Pediatrics 2011 11:16.

\section{Submit your next manuscript to BioMed Central and take full advantage of:}

- Convenient online submission

- Thorough peer review

- No space constraints or color figure charges

- Immediate publication on acceptance

- Inclusion in PubMed, CAS, Scopus and Google Scholar

- Research which is freely available for redistribution

Submit your manuscript at www.biomedcentral.com/submit
Biomed Central 